\title{
The Effects of the New Energy Regime on Economic Capacity, Production, and Prices
}

\author{
ROBERT H. RASCHE and JOHN A. TATOM
}

T HE quadrupling of OPEC oil prices in late 1973 and early 1974 had a profound and permanent impact on the U.S. economy. The initial impact was an explosion in the prices of most goods and services, as well as the longest and most severe decline in national output since the $1930 \mathrm{~s}$. The recession trough occurred over two years ago and the rate of inflation has fallen substantially since 1974 . While the inflation rate remains quite high by historical standards, the primary focus of concern, at least in official circles, seems to have shifted toward the persistence of an unacceptably high unemployment rate and the associated loss of national output. More importantly, the mounting concern over the immediate problem posed by unemployment seems to have obscured the permanent effect of the energy price revision.

The large increase in the price of energy in 1974 permanently reduced economic capacity, or the potential output of the U.S. economy, by four to five percent. The productivity of existing capital and labor resources was sharply reduced. Policy discussions which fail to account for the permanence of these changes, especially in the face of persistent unemployment, contribute to an overstatement of the benefits to be obtained from a conventional policy of aggregate demand stimulus.

In order to clarify the gains which may be expected from a stimulative economic policy and the accompanying inflation risks, it is useful to examine the impact of the energy price revision on prices, production and employment. ${ }^{1}$ To facilitate this discussion,

\footnotetext{
1 Most of the discussion of the economic impact of the OPEC action has focused upon its effects npon aggregate demand. However, several recent studies have indicated that the nam tion's excess capacity may not be as large as some data shows. Among these studies are: Denis S. Karnosky, "The Link Between Money and Prices - 1971-76," this Review (Jnne 1976), pp. 17-23; A. Nicholas Filipello, "A Qtestion of Capacity,"Business and Goternment Outlook (Fall 1976), pp. 1-3; and Barry "Bosworth, "Capacity Creation in BasicMaterials Industries," Brookings Papers on Economic Activity $(2: 1976)$, pp. 297-341. A contrary viow is presented by Albert J. Eckstein and Dale M. Heien, "Wstimating Potential Output for the U, S. Economy in a Model Framework," Achieving The Goals of the Emptoument Act of 1946 - Thirtieth Anmersary Review, U.S, Congress, Joint Economic Committee, 94th Cong., 2nd sess., Decenber 3, 1976 , pp. I-25.
}

we will first develop the concept of a firm's capacity output. This concept allows for analysis of the effects of a change in the price of energy on a firm's cost structure, capacity output, employment, and product price using a standard microeconomic model of the firm. Such an analysis is basic to an understanding of potential output and the transitional and permanent impacts of the OPEC price actions since 1973.

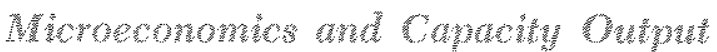

The notion of economic capacity is fundamentally a short-run concept. There is no limit to the output a firm could produce efficiently if it could command sufficient amounts of each of the resources it employs. From a long-run perspective, an efficient firm would tend to use more of each of the resources it employs to produce at a higher output rate. However, some resources are, as a practical matter, fixed or given for some period into the future. This fixed nature of some resources characterizes the short run. For any amount of fixed resources only one output rate can be produced using an efficient long-run method. This output rate is the economic capacity of the firm. Firms have a cost-saving incentive to produce at capacity output or to have an amount of fixed resources that allow the production of their desired output at the lowest cost possible.

The concept of a firm's capacity may be seen more clearly by looking at the cost structure of the hypothetical firm of economic theory. ${ }^{2}$ The cost structure is derived from the "production function" of the firm and the prices of resources used by the firm, such as labor, capital and energy. A production function defines the maximum output attainable given the

\footnotetext{
2Such a cost structure is more fully discussed in the microecononic section of most principles of economics texts. A thor ough development of the cost structure of the firm may also be found in C. E. Ferguson and S. Charles Maurice, Economic Analysis, rev ed. (Homewood, Illinois: Richard D. Irwin, Inc., 1974), Chapters 6 and 7 , pp, 161-232, The best discussion and argument for the concept of economic capacity used here is that by George Stigler, The Theory of Price, 3td ed. (New York: The Macmillan Company, 1966), pp. 156-58.
} 
state of technology, for any set of resources.; For each rate of output, technology and the prices of resources dictate the lowest cost method or combination of resources required.

Figure I shows the relevant long-run and short-run cost structure of the firm. In the long rum, when the firm is free to change the employment of all resources, the unit cost or long-run average cost (LAC) of any output rate is constant. ${ }^{4}$ Given the price of each resource, the firm can choose the method of producing any output rate at the lowest total resource cost or unit cost ( $\mathrm{C}$ in Figure I). Any other output rate could be produced by varying proportionately each of the resources used with the lowest cost method. Since total resources cost is also proportionate to resource employment, unit cost (C) is independent of output. In the long run, the cost of producing an additional unit of output, the marginal cost, is the same as the average cost of a unit of output.

For any amount of fixed resources, the output rate which can be produced with the minimum long-rum cost method is capacity output. In the short run, any output, other than capacity, will require a higher cost method of production than that indicated by the longrun average cost. Thus, for any level of capital which is fixed in the short run, the short-run average cost of output, $\mathrm{SAC}$, is above the long-run average cost curve, except at the capacity output level. Of course, the larger is the amount of capital the firm has, the larger is its capacity output. In the short-run, higher cost methods are required to obtain additional output since only variable resources may be increased. As output expands, each unit of a variable resource has less of the fixed resource with which to work so the productivity of variable resources declines. Correspondingly, the cost of additional output, the shortrum marginal cost (SMC), rises as the output rate expands. This cost is only the same as the long-run

\footnotetext{
"The production function is based upon technical efficiency. 'The more popular' notion of capacity, the maximum output attainable for a given set of resources is, by definition, in cluded in the prodiction function and does rot depend inpon resource prices.

The production process, for simplicity, is assumed to be char acterized by "constant retums to scale," or proportionate changes in the use of each resonice (change in scale) will allow output to be changed proportionately.

5 The SAC curve is U-shaped. At low rates of output, the major component of cost is the cost of the frxed resomires. As ontput expands, the firm "spreads its overhead" over more units producing a larger output at a lower unit cost. As ontput is expanded beyond the capacity level, the unit cost of variable resources becomes an increasing share of unit cost and tlie cost effect of using highet cost (lower productivity) methods of production is dominant and raises the unit cost.
}

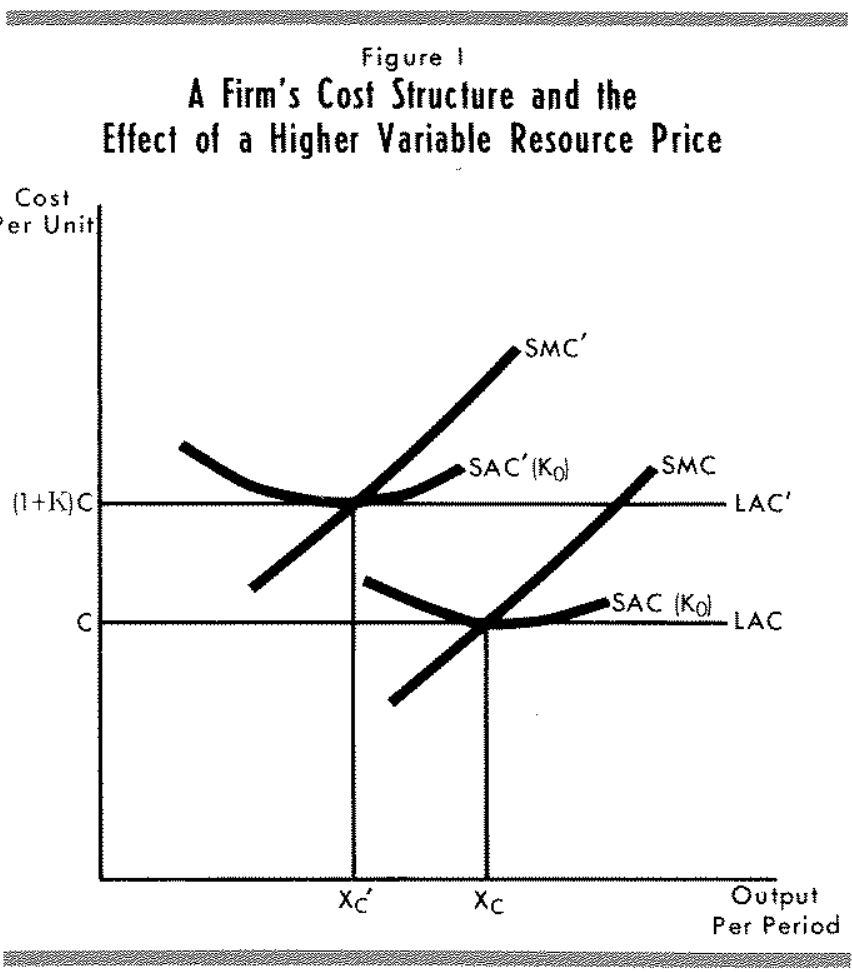

marginal cost at the output which uses the optimal long-run method of production, or capacity output.

The cost structure is a major factor in the output decision of a firm. For example, consider the profit maximizing competitive firm which is a "price-taker," able to sell as much as it chooses at a given market price. For such a firm, the relevant short-run supply curve is the SMC curve in Figure I. For any given market price, the firm maximizes profit by producing the output rate where marginal cost, SMC, equals price." The cost structure is important in the longm rum as well. The firm will not continue operating in an industry where losses (the inability to cover the cost of using capital, labor, and energy resources) are incurred. The minimum long-run supply price is (C) in Figure I. Moreover, if the firm earls economic profit in the short ran, it has an incentive to expand its capital and capacity output. In addition, the existence of economic profit attracts new firms into the industry. As output expands, the product price tends to fall to induce customers to buy the larger output.

\footnotetext{
TTechnically, the short-run supply curve-is only defned above the minivim level of unit expenditures on variable resources. If the market price were below this level, there would be no output at which the firm could cover the cost of its variable resources. The proft-seeking firm would shut down, restricting losses to the cost of the fixed resourcts. Note atso that if the market price equals (C) in Figure $I$, the firm maximizes profit by producing the capacity output rate. While the firm "breaks even" there, it earns a competitive rate of retimn on its capital since this return is included in the unit fixed cost and $S A C$.
} 
The product price will tend to fall to (C) where the long-run incentive to expand capital and capacity output is eliminated. ${ }^{7}$

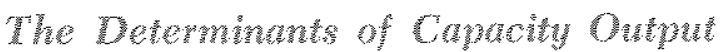

Capacity output is determined by the stock of capital which a firm has, and its long-rum average cost. The latter, in tum, depends upon the market price of each resource employed and technology. Changes in either resource prices or technology will change the economically efficient means or production in the long run and shifts the long-run average cost curve. Moreover, such changes, except for a change in the price of the fixed resource, will shift the firm's shortrun supply. ${ }^{8}$

The effect of a one percent increase in the price of a variable resource on the cost structure and capacity output of a firm is also shown in Figure I. An increase in the price of a resource raises the long-run average cost and supply price of output. The extent of the rise in long-rum average cost depends upon the share in total cost of the resource whose price has increased. A change in the price of a resource whose cost is a very minor proportion of total output cost will have very little impact on unit cost, as compared to a resource whose cost is a major share of unit cost.

In particular, each one percentage point rise in the price of a resource will add $\mathrm{K}$ percent to the longrun average cost, where $K$ is the share of this resource in total cost." For example, a one percent increase in the market wage rate of workers in a firm where labor costs account for half of total costs will tend to raise the long-run unit cost by one-half of one percent.

The short-run supply decision also is affected by an increase in the price of a variable resottce. An increase in the price of a variable resource raises the cost of the resources necessary to produce more output. Thus, the short-run marginal cost of output also increases. Moreover, it increases more than short-run

\footnotetext{
The concept of capacity is not restricter in its relevance to the cases of competitive fims having constant-returns-to-scale production processes. For any market structure and regardless of returns to scale, any firm has a cost-saving incentive to manage capital resonrces so that production of any desired ontput ocours at capacity.

SSince we are primarily concerned with the effect of changes in resource prices on capacity, the analysis of technological change is not pursued here.

${ }^{A} \mathrm{~A}$ rise in the price of capital increases capacity output. Fixed costs do not affect the narginal cost of ontput in the short rum. Since average cost, both short- and long-rm, rise, capacity rises to the output evel where long-rum average cost intersects the intial short-run marginal cost cirve.
}

average cost. ${ }^{10}$ If there is more than one variable resource, changes in the mix of variable resources affect the size of the upward shift in each cost and the result is more difficult to specify. However, when the resource whose price increases is a "substitute" for capital in the production process the analysis of the simple case and the results depicted in Figure I hold. ${ }^{11}$ The percentage reduction in a firm's capacity output is identical to the percentage rise in its long-run average cost. At the new capacity output, the firm possesses its optimal amount of capital, given the new set of resource prices, and it employs exactly the capital and labor which were efficient before the rise in the price of energy. Only energy employment declines as capacity output declines..$^{12}$

The effect of a rise in the price of a variable resource such as energy is to reduce capacity output and raise the long-run supply price, the changes being greater, the greater is the share of energy in the total cost of each product. Products which rely more heavily upon energy have larger losses in capacity output and their long-run price is increased relatively more than that of other goods.

\section{Astimates of the Change in Manufuctung

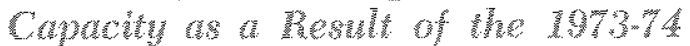 Change in thergy prices}

The discussion above suggests that an estimate of the capacity loss in U.S. manufacturing due to the

to A simple example illustrates why this is the case. Stepose labor is the only variable resource in the short rm. A given percentage increase in the wage rate will proportionately increase the cost of both the labor currently employed per unit of output, and the labor necessary to produce an aditional unit of output, the marginal cost. Since the fixed cost of output is unchanged, the nuit cost of ary level of output rises less than the percentage increase in labor costs. If each fim initially operated at capacity output, the marginal cost rises more than shortmu average cost at that output, and capacity output declines.

11 A resource is a "substutute" for capital, if efficient production of some ontput requires that a rise in the price of the rem source lowers the optimal employment ratio of the resource to capital For example, energy and capital are substitutes if a rise in the price of energy relative to that of capital services catises the eficient firm to lower its employment of energy pen mit of capital services to produce a given rate of ontput.

12The resulds in this paragraph are derived in our unpubished paper, "Firn Capacity and Factor Price Changes." The conclusions reguire that profuction is characterized by a "partial elastucty of substitution" between energy and cap" ital and between energy and labor equal to one. This means an $X$ percent rise in the price of enengy relative to the price of capital (or labor) causes least-cose production of any output to renine $X$ percent less energy relative to capital (or labor) employnent. This appears to be an accurate characterization for production in nine industrial nations, including the United States. See J. M. Grifhm and P. R. Gregory, "An Intereominty Translog Model of Energy Substitution Responses," The American Economic Review (December $1976)$, pp. $845-5 \%$ 
sharp increase in the price of energy could be obtained if measures were available on the change in capacity by industries. The discussion of the microeconomics of capacity indicates that information would be required on parameters of the production functions of these industries, and on the size of expenditures on energy by industry, as well as a measure of the increase in energy prices over the period. Unfortunately, no complete set of estimates of the relevant production function parameters by industry exists.

An alternative is to consider estimates of the production function parameters for the aggregate of all manufacturing. A recently published study, which overcomes a number of statistical problems inherent in previously published estimates, provides estimates of the required information concerning the aggregate production function for manufacturing in nine industrial countries, including the United States. ${ }^{13}$ This study supports the conclusion above that the percentage response of capacity output to a one percent change in the price of energy is just equal to the share of energy costs in total factor costs. The study suggests that this cost share was quite stable throughout the $1960 \mathrm{~s}$ at around twelve percent of total factor costs. Thus, an unexpected ten percent increase in energy costs, given wages and the capital stock, should produce approximately a 1.2 percent decrease in capacity of the U.S. manufacturing sector.

The behavior of the price of energy relative to the price of output is presented in Chart 1 , where a relative price index has been constructed by dividing the wholesale price index for fuels, related products, and power by the deflator for private business output, adjusted to a basis of $1972=1.0$. As can be seen from the Chart, this relative price series trends downward through the 1960s, is fairly stable from 1968 through 1972 , rises sharply from the fourth quarter of 1973 through the third quarter of 1974 , and then becomes relatively stable around a value of 1.6 until mid-1976. The wholesale price of energy increased 45.3 percent from the fourth quarter of 1973 through October 1974. This increase, multiplied by a cost share of 0.12 suggests a loss in manufacturing capacity of about 5.4 percent.

\footnotetext{
13 See J. M. Griffin and P. R. Gregory, "An Intercountry Translog Model of Energy Substitution Responses." They conclude that production can be considered to be of the Cobb-Douglas form in the energy resource. Their estimates are constructed inder the assumption of constant returns to scale. Under these conditions, the partial elasticities of stbstinution between capital and energy and between labor and energy are both equal to one, as required in the analysis in the previous section.
}

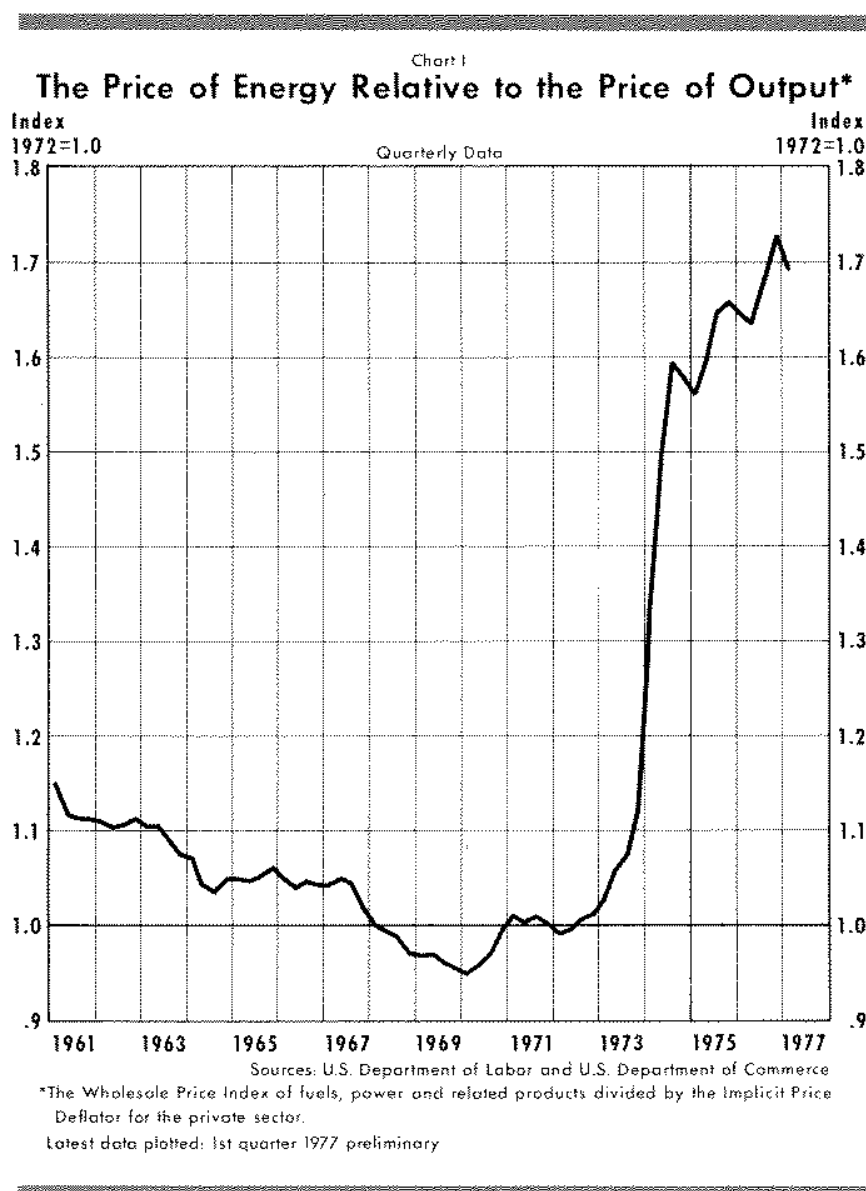

Energy prices were not the only factor prices which were observed to rise during this period. Over the period (IV/1973 through III/1974), actual hourly compensation rose by 7.9 percent. According to the Griffin and Gregory estimates, an increase of labor costs of this magnitude in the manufacturing sector of the U.S. economy should have reduced capacity by an additional 0.4 percent. In total, the change in economic capacity as a result of changes in factor prices over this period of time can be estimated to be on the order of five percent. ${ }^{\text {tt }}$

It is generally accepted that the U.S. economy was operating at effective capacity during the latter half of 1973. The important question is where did the economy operate relative to its new, lower, economic capacity in the latter part of 1974. Employment in

\footnotetext{
1: The sum of the effects from energy price changes and wage changes is 5.8 percerts. This estinate implicitly assmes that the price of capital services remained unchanged over this period. Alternatively, it could be assumed that the price of capital services rose proportionally to the increase in wayes. Such an increase would off set (see footnote 9 ) the computed reduction in capacity by 1.4 percent, for a net reduction of 4.5 percent. The five percent reduction chosen above represents a midpoint of this range.
} 
mantufacturing declined by 1.8 percent from the fourth quarter of 1973 through October 1974. Over the same period, the average work week (of production workers) in manufacturing declined by 1.5 percent for a reduction in total hours per week of about three percent. The Griffin-Gregory estimates suggest that the reduction in capacity of the order of magnitude suggested above should have been accompanied by a zero to 1.5 percent reduction in employment. Given the statistical error associated with the production function estimates, the data on the behavior of employment over this period appear to be roughly consistent with a movement from one point of full capacity utilization to a second point of full capacity utilization.

The Federal Reserve Board's Index of Manufacturing Capacity Utilization was 87.8 and 87.7 percent in the last two quarters of 1973 , respectively. By October 1974, the month immediately prior to the sharp drop in industrial production and the sharp rise in unemployment which characterized the rest of the 1973-75 recession, this index had fallen to 83.4 percent. If this index does not capture the impact of changes in relative factor prices, and if the economy was operating at full economic capacity in October 1974, then the index should understate capacity utilization by the amount of the capacity loss. The decline of the index to this point in time is 5.1 percent which is the same order of magnitude as suggested by the Griffin-Gregory production function estimates.

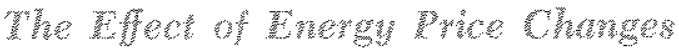

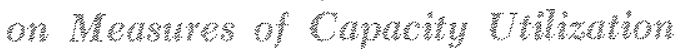

A crucial question is whether or not the conventional capacity utilization indices measure the impact of a change in relative factor prices. There is no question that the Wharton Index fails to measure such effects, since it measures capacity by extrapolating peak-output to peak-output trends. ${ }^{15}$ The Federal Reserve Board Index is constructed by utilizing data from periodic surveys on capacity utilization such as the McGraw Hill capacity survey and interpolating using the behavior of the Federal Reserve Industrial Production index for manufacturing. As a result the Federal Reserve capacity utilization index has two general properties: (1) the cyclical movements approximate those of the industrial production index, with the growth trend removed; and (2) the average

15. A description of this series may be found in F. Gerard Adams and Robert Summers, "The Wharton Indexes of Capacity Utilization: A Ten Year Perspective," Proceedings of the Business and Economic Statistics Section, 1973 (Washingtor, D.C.: American Statistical Association, 1974), pp. 67-72. atilization rates over time and the long-term movement in such rates are determined by the estimates of utilization rates as reported in the various surveys. ${ }^{10}$ The important question is, therefore, whether the survey data would pick up the change in the utilization of economic capacity.

The concept of capacity which the surveys attempt to measure has been labeled "maximum practical capacity." 17 This approach seems to ask how much cotuld be produced with existing facilities if they were run under normal "full-time" operating conditions. It does not seem to ask whether such a level of operations would be efficient given existing factor prices. This interpretation is reinforced by the testimony of Mr. Douglas Greenwald of MoGraw Hill before the Joint Economic Committee. In discussing the notion of capacity in the McGraw Hill Surveys he stated:

Thus it was decided to let companies set their own definitions of capacity, and we only asked that the respondents stick to their definitions. This, of course, leaves open such questions as number of shifts of operations, treatment of low grade, standby capacity, and final assembly versus intermediate capacity. But, in general, companies follow a commonsense definition of capacity, such as maximum output under normal work conditions. ${ }^{18}$

The authors of the description of the recent revision of the Federal Reserve Board (FRB) capacity utilization index appear to agree that the concept of capacity measured by the survey data does not capture the effects of changes in relative factor prices: "This version of capacity (maximum practical capacity) is similar to our prior notion of engineering capacity in that no explicit recognition is given to the effects of changing price relation over the cycle." ${ }^{\prime \prime}$ Thus, it would appear that the measured indices would not capture the impact of changes in economic capacity as defined above, and that the measured utilization indices would underestimate utilization by the amount

10 Federal Reserve Bulletin (November 1976), p. 894.

${ }^{17}$ See Survey of Current Business (July 1974), pp. 54-5. This measure is defined as the maximum outpat which could be produced using existing facilities while at the same time "following the company's usual operating practices with respect to the use of productive facilities, overtime, work shifts, holidays, etc." and assuming "product mix at capacity which is most nearly similar to the composition of your actual output." lbik, p. 50.

18U.S. Congress, Joint Economic Committee, Subcommittee on Ecomonic Statistics, Measures of Productive Capacity, 79th Cong., 2nd sess., May 14, 1962, p. 4.

19L. Forest and R. Raddock, "Federal Reserve Measures of Capacity Utilization," unpublished memorandum, (Washington, D.C.: Division of Research and Statistics, Board of Governors of the Federal Reserve System, 1977), p. 13. 
of the factor price effect.20 Adjusting the Federal Reserve Board index for October 1974 up by five percent gives an estimated utilization rate of 87.6 percent, essentially the same as in the fourth quarter of 1973.

Two strategies could be adopted for adjusting the published figures since the end of 1974. It could be assumed that the survey respondents gradually adjust their concept of "normal operating conditions" over time. In the near term it seems unlikely that this would happen. First, the emphasis in the survey construction is on historical conditions in the particular industry. Second, the emphasis is on inertia: respondents should choose whatever definition of normal operating conditions they wish, but then they should "stick to that definition," Over a longer period of time, some reduction in the bias of the measured index will take place as the capital which suffered the capacity loss depreciates, and is replaced by new capital. Chart II is constructed assuming a constant downward adjustment in capacity as measured by the Federal Reserve Board equal to five percent of the capacity measure for October 1974. The revised capacity measure is divided into the industrial production index to give the adjusted index of capacity utilization plotted in the figure. It is difficult to know how to handle the first three quarters of 1974 , since the relative price of energy was changing rapidly during this period of time, and since the published index of capacity utilization is based on interpolations between the survey dates. For lack of a better alternative, we show the utilization rate as constant over these quarters.

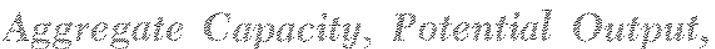 ase Samply}

Construction of an aggregate or economy-wide measure of capacity is not, in general, a straightforward adding of the capacity measures of the individual firms. The attempt by all firms to move to operations at their computed capacity levels, may cause changes in factor prices. Such changes in factor prices would shift all of the cost curves of the individual

20The recent revisions in the FRB index might be cited as evidence that this index captures some or most of the pernanent loss in capacity because of the change in the relative price structure. An examination of the relationship between the FRB index and the Whaton index before and since 1974 fails to provide any stroner support for such a hypothesis. The annulal FRB capacity ntilization index was regressed on the annual Wharton capacity utilization index from 1951 through 1973. Linear and log-inear specifcations were constructed in level and first difference forms. When any of these specifications is used to simulate the FRB index from 1974 through 1976, the prediction ertors are less than one standard error from the actual value of the index in all three vears.

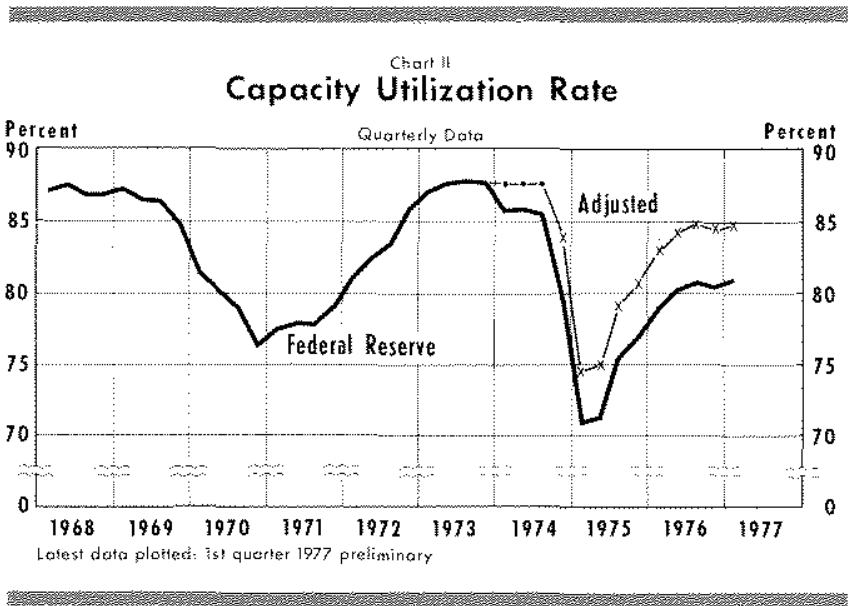

firms and, hence, would alter capacity. The computation of aggregate capacity requires the summation of the capacity estimates of all individual firms based on the factor prices which would actually be realized if all of the firms operated at their capacity level. ${ }^{21}$

Nevertheless, the aggregative problems may be partially avoided and the effects of an energy price change on United States production can be analyzed, by proceeding in stepwise fashion. Assume that aggregate output is produced by firms like the hypothetical firm described above. Energy prices are, since late 1973. determined on a world market, so it can be assumed that the United States faces a perfectly elastic supply curve for this resource. ${ }^{22}$ Finally, assume the labor supply curve of the traditional textbook Keynesian model, namely that the aggregate labor supply is perfectly elastic at a given nominal wage rate, at least up to some "full-employment" quantity. Under these circumstances the aggregation problem discussed above is avoided, and the appropriate measure of aggregate economic capacity in the model is the summation of the economic capacity of the individual firms. Aggregate capacity is only one point of the short-run aggregate supply curve of the economy. Under the assumed conditions regarding factor markets, it is possible to construct an aggregate supply curve such as $S_{1} S_{1}$ in Figure II, for the entire economy by summing the relevant portions of the

${ }^{21}$ This problem is discussed by Lawrence $R$. Klein, "Some Theoretical Issues in the Measurement of Capacity," Econometrica (April 1960), pp. 272-86.

22This is the traditional small-country assumption frequently found in the international trade literature. In this particular market, it appears to be an appropriate description of behavior over the past few years. Inifially we shall assume that the nominal price of energy is given, in the next section this assumption is altered to more accurately reflect the recent situation where the relative price of energy is determined abroad. 


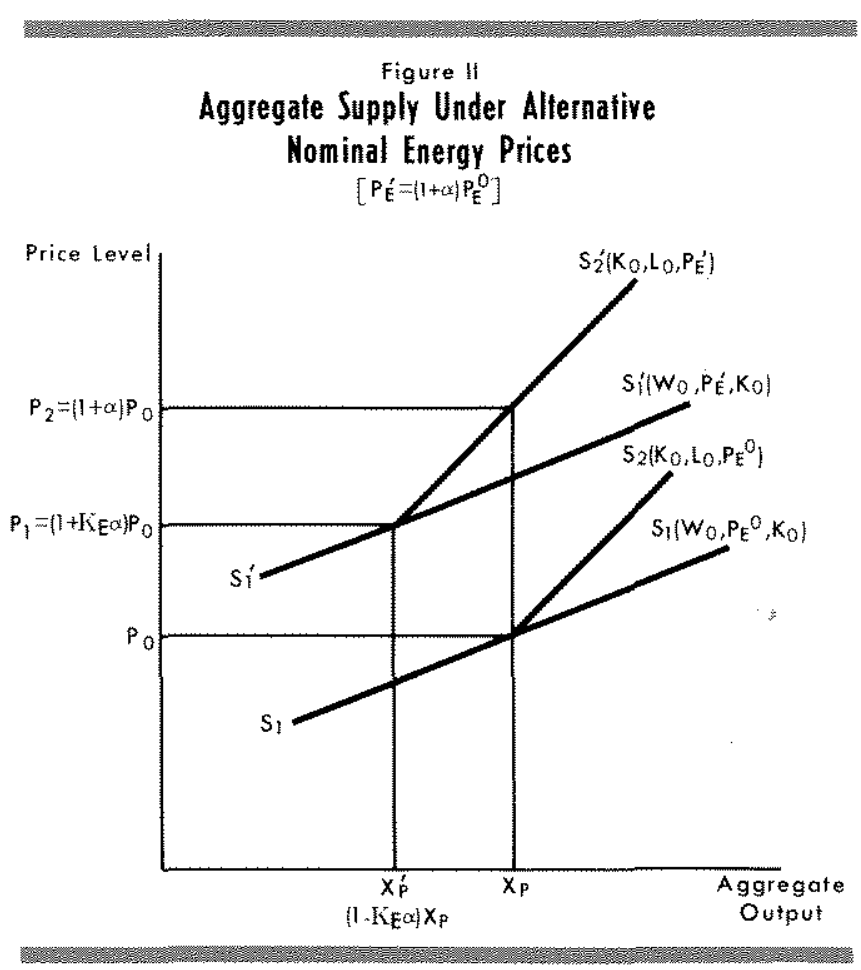

short-run marginal cost curves across all firms. ${ }^{23}$ Thus, along $S_{1} S_{1}$, nominal wages, $W_{0}$, the nominal energy price, $\mathbf{P}_{\mathbf{E}}^{0}$, and the stock of capital, $\mathbf{K}_{\phi}$, are held constant.

An important constraint, for the aggregate economy, remains to be taken into account. The economy is only a price taker in the labor market up to the existing supply of labor or "full employment." Attempts to expand output beyond that produced with full utilization of capital and labor, result in higher wages and prices with little or no impact on aggregate production. This level of output is generally referred to as "potential output." It has become common to consider the aggregate supply curve being vertical at potential output. Such a vertical segment would occur along $S_{1} S_{1}$ in Figure II at the output $X_{p}$.

In the context of the discussion here, the appropriate supply curve, once full utilization of labor is reached, is not vertical. While attempts to expand output beyond $X_{p}$ result in higher wages and prices, with

\footnotetext{
23Changes in one of the two variable factor prices still pose aggregation problems. The results for the firm indicate that an increase in the price of energy would seduce capacity output and raise the long-run supply price of a product more, the more important (as measured by the cost share) energy is to production. Hence, relative commodity prices will be affected in both the short run and long ran due to the higher energy mrice. We may abstract from the interindustry changes in relative prices and focus on potential output and capacity changes by considering the aggregate production function implicit in discussions of potential output.
}

no additional labor or capital entering production, the economy is free to expand its employment of energy. Given a nominal market price of energy, higher output prices can lead to increased output through the use of more energy intensive operations. The aggre gate supply curve beyond $X_{\eta}$ will be steep but not vertical, as along $S_{2}$ in Figure II.

Suppose that initially every firm is producing its capacity output and the economy fully utilizes capital and labor, producing output $X_{\mathrm{p}}$ in Figure II at its corresponding price level at the kink in the supply curve $S_{1} S_{2}$. An $\propto$ percent rise in the nominal price of energy, $P_{E}$, will shift the aggregate supply curve. The shift in the $S_{1}$ segment of the aggregate supply curve may be found by the same reasoning as applied to the firm supply curve. The relevant parameter is the share of energy, $\mathbf{K}_{E}$, in the total factor cost of aggregate output. Capacity output falls initially by $\mathrm{K}_{\mathrm{E}}$ percent for each percentage point increase in $P_{E}$, to $X_{E^{\prime}}^{\prime}$ in Figure II. Moreover, as in the case of the firm, capital and labor employment will be the same at $X_{p}^{\prime}$ as at $X_{n}$, and the price level of this output will rise by a percentage equal to the factor share, $K_{E}$, for each percentage point rise in $\mathrm{P}_{\mathrm{E}}$. The reduction in output is associated with a reduction in energy usage. Since both capital and labor would be fully utilized at output $\mathrm{X}_{\mathrm{p}}$, the kink in the new aggregate supply, $S_{1}^{\prime} S_{2}^{\prime}$ occurs at that output.

It should be noted that output $\mathrm{X}_{\mathrm{n}}$ could still be produced and would be, if the price of output were sufficiently higher, at $P_{2}$. If the output price and other resource prices rise by precisely the percentage increase in the nominal price of energy, firms would be willing and able to produce exactly their original output, $\mathrm{X}_{p}$, utilizing the original methods of production.

An analysis of how this may come about is shown in Figure III. As the supply curve shifts and the price level rises above $P_{o}$, less output will be demanded. Policymakers may take actions such as monetary expansion to maintain real output at $\mathrm{X}_{\mathrm{p}}$, by shifting aggregate demand. While full employment would exist at output $\mathrm{X}_{\mathrm{p}}^{\prime}$, policymakers might face pressures to expand demand since output and the real return to capital and labor owners will have fallen at price level $\mathbf{P}_{1}$.

As the level of prices rises to $P_{2}$, increased competition for fixed capital and labor resources raises their nominal prices and shifts the $S_{1}^{\prime}$ curve to $S_{1}^{\prime \prime}$. The higher price of output and other resources reduces the relative price of energy, providing an incentive to adjust energy employment back toward its original 


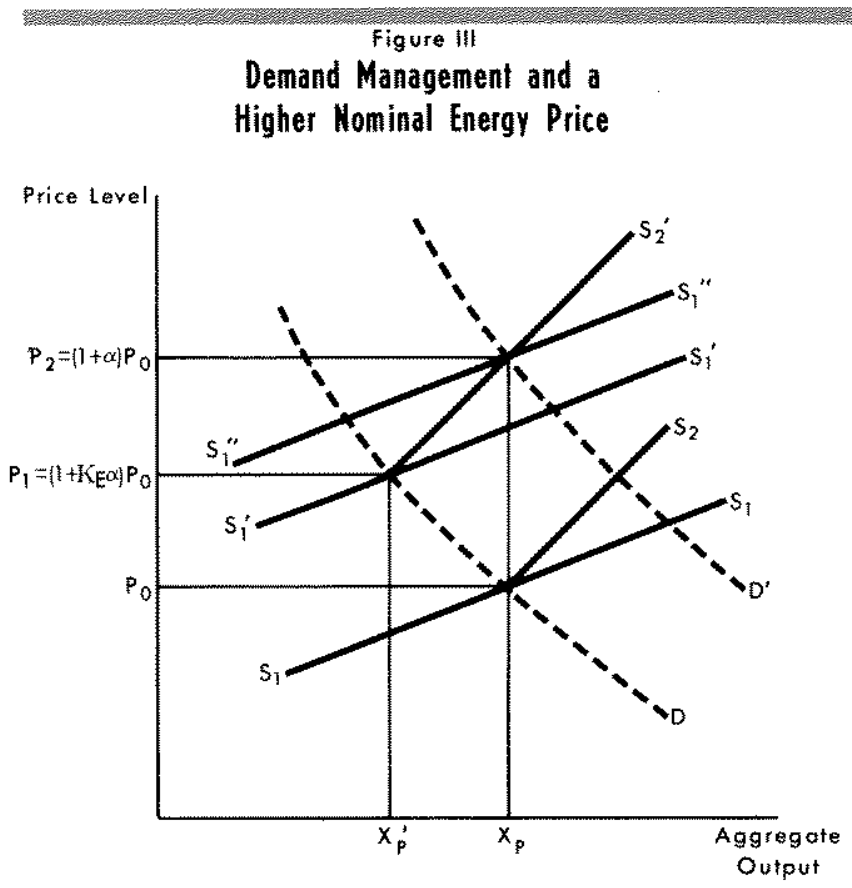

rate of usage. Thus, to maintain real output at its original level, commodity and factor prices must rise by the same percentage as the increased energy cost to restore all relative prices to their original values. The two essential ingredients of this result are the accommodative expansive demand management policy and the fixed and higher nominal price of energy in world markets.

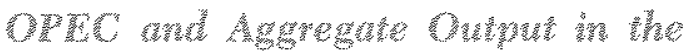 Yristed Shates}

The relative price of energy presented in Chart I indicates a large jump in late 1973 and 1974 which has not been eroded by demand growth and increases in the price level. In the analysis above, the relative price of energy initially rises, but the accommodative demand management policy is able to effectively erode the gain to energy producers through inflation. The relative price of energy is restored to its original level.

The pricing actions of OPEC apparently were not intended to be so easily frustrated. The relevant price which OPEC is able to dictate as the dominant energy producer is the price of energy relative to that of output. Attempts by U.S. firms to move along the $S_{2}^{\prime}$ curve in Figure III are frustrated by further increases in the nominal price of energy. The appropriate aggregate restriction on the supply curve $S_{1}$ (or $S_{1}^{\prime}$ ) is not that indicated by $S_{2}$ (or $S_{2}^{\prime}$ ). Instead; after the institutional change imposed on the world energy
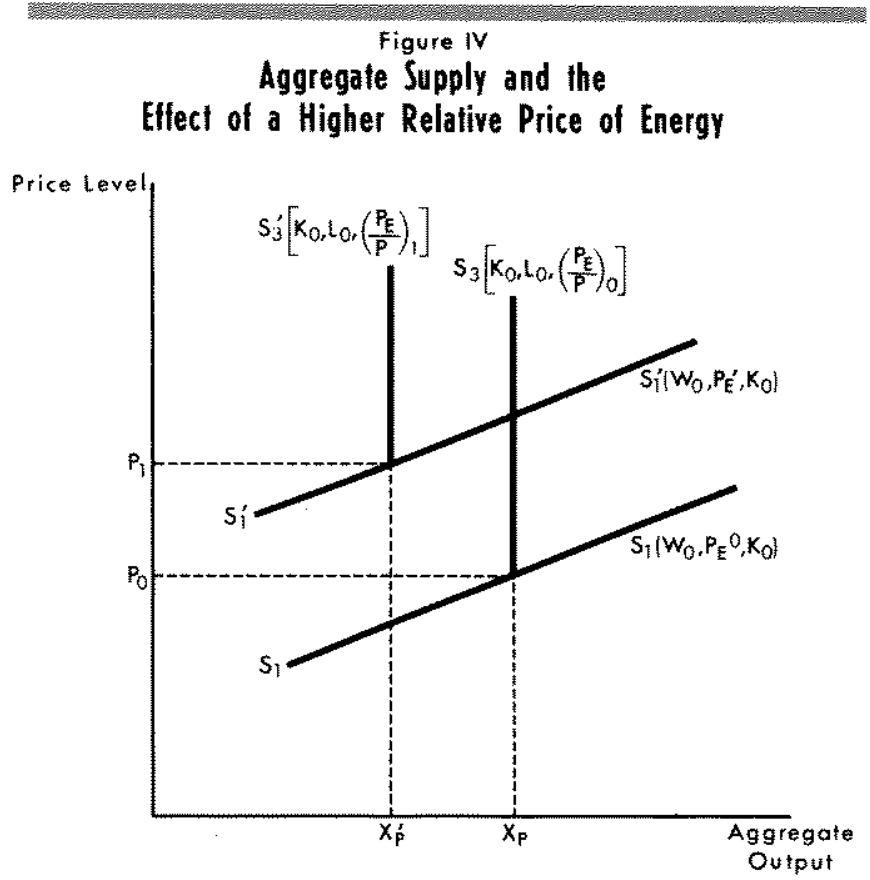

market, the appropriate restriction is a given relative price of energy. Given this relative price and an existing amount of capital, full utilization of labor occurs at a price level where labor costs relative to output prices warrant hiring all the labor available. Increases in output prices, beyond this point, result in no incentive to expand energy employment and merely bid up the nominal prices of the fully employed labor, capital, and energy. Such a supply restriction implies the vertical segment of the aggregate supply curve discussed earlier. In Figure IV, this supply restriction is depicted as $S_{3}$ at the capacity output level, $X_{p}$. The aggregate supply curve is $\mathrm{S}_{1} \mathrm{~S}_{3}$.

An increase in the nominal price of energy raises the $S_{1} S_{1}$ segment of aggregate supply in precisely the same manner and amount as in Figure II. Again, at output $\mathrm{X}_{\mathrm{v}}^{\prime}$ and price level $\mathrm{P}_{1}$, there is the same utilization of capital and labor as at $X_{n}$. However, in this case, the new relative price of energy shifts the vertical segment of the aggregate curve to $S_{3}^{\prime}$. Thus, there is no price level at which the economy may produce its original level of potential output. Both capacity output and potential output fall to $\mathrm{X}_{\mathrm{p}}^{\prime}$. If excess demand exists at $P_{1}$, or if policymakers create an excess demand at price $P_{1}$ through expansionary policy, nothing happens to aggregate output. In such situations, the price level will simply rise inducing employers to bid up nominal resource prices for the fully-employed capital and labor resources as well as the dollar prices of energy. 
The increased relative price of energy, according to this analysis, caused a permanently higher level of prices and permanent reduction in potential output, as well as reducing firms' capacity output and altering relative commodity prices. These effects occur in dependently of changes in the level of employment of labor and capital and may not be offset by demand management policies. The only way to recover the loss in potential output and capacity would be the restoration of the prior relative price of energy. ${ }^{24}$

\section{The Loss of potential Output in 1974 and the Economic Ontook}

Data on potential output, recently constructed by the Council of Economic Advisers (CEA), indicate that the economy was operating essentially at its potential in late 1973. Table I shows potential output and actual real GNP (1972 dollars) since IV/1973. From IV/1973 to IV/1974, real output fell 4.1 percent (about $\$ 51$ billion) while potential GNP was estimated to rise 3.5 percent or about $\$ 44$ billion. Thus, in the fourth quarter of 1974 , there is an estimated. "gap" of $\$ 96.7$ billion.

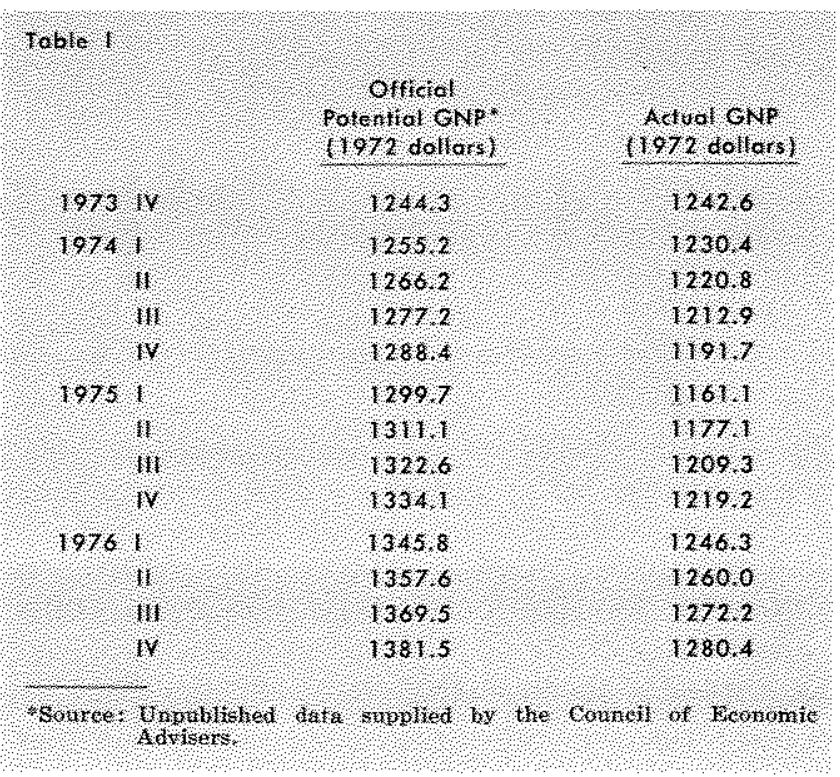

The growth in potential output reflects growth in the labor force, adjusted for its age-sex composition, and growth in the capital stock over the year. In particular, the estimate assumes constant or trend growth in

240 course, over time labor force growth and capital accimulation would increase potential ontput so that eventually the old level of potential outpit is restored. The conclusion above is that the labor and capital existing at any time could produce a larger potential output, in the absence of the energy price increase.

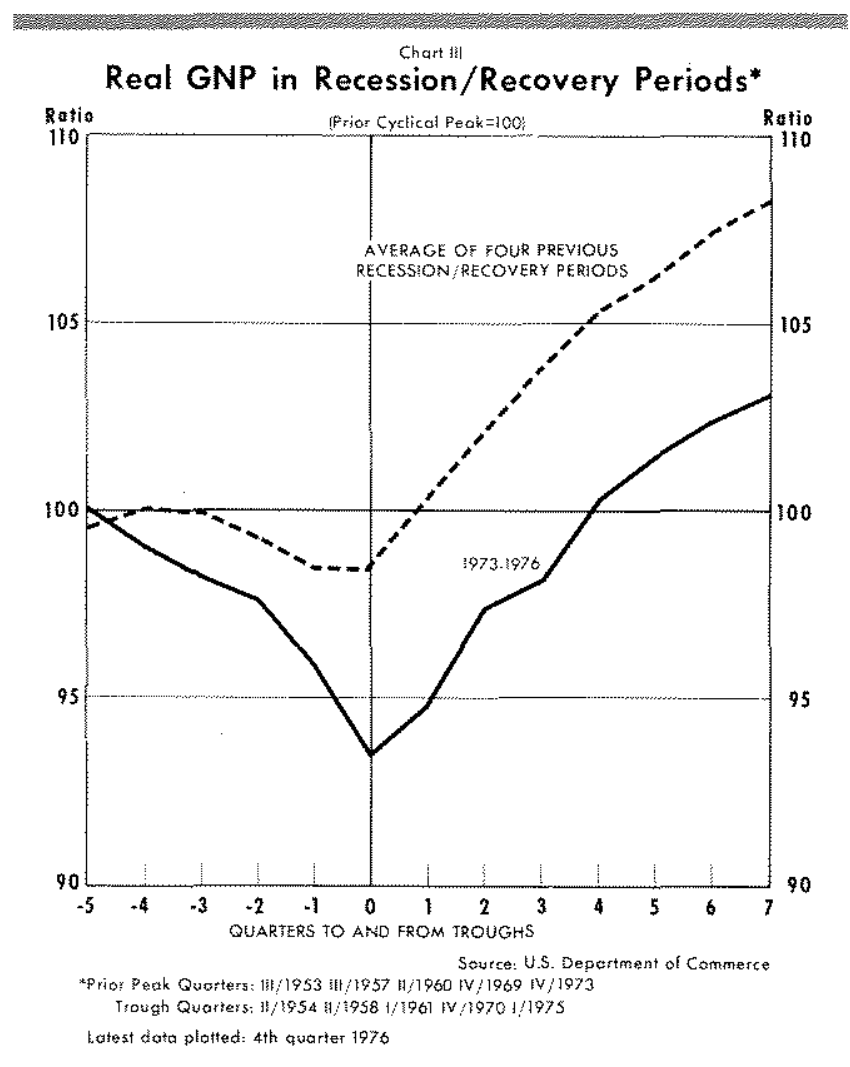

productivity of resources. Thus, the potential estimates do not include changes in potential output due to a change in the relative price of energy and the consequent decline in the productivity of capital and labor described above. ${ }^{25}$

Since some growth in the capital stock occurred in 1974, it may be inferred that the effect of the OPEC mandated energy price change (IV/1973 to IV/1974) reduced U.S. capacity and potential output by more than the actual 4.1 percent decline in real output. An estimate of five percent is roughly the order of magnitude indicated by a monetarist model of 1974 price and output developments. ${ }^{26}$

A five percent estimate of the loss in potential output or reduction in the productivity of capital and labor resources is also the correct size to explain an "output

225The Council of Economic Advisers, Economic Report of the President, 1977 , pp. 52-5, indicates an awareness of this permanent decline in productivity, and even suggests the magnitude of the decline in potential output to be about $\$ 30$ billion (1972 dollars) by 1976. The CEA indicates that over the near term, productivity data should demonstrate whether or not the productivity decline is permanent, and that such proof will determine the need for a revision of its estimates of potential GNP.

26ee Kamosky, "The Link Between Money and Prices." 
gap" recently noted by the Congressional Budget Office (CBO). ${ }^{27}$ The CBO pointed out that, after six quarters of recovery, real GNP was about five percentage points below the rate indicated by the experience in prior recoveries. Furthermore, the CBO attributes two percentage points of the unusually high unemployment rate to this output gap. ${ }^{28}$

Chart III shows the pattern of previous recessions and recoveries discussed by the CBO. Real GNP is measured relative to its rate at the prior cyclical peak and an average of this index of output is given for the four prior recession-recovery periods. The chart shows that on average, after six quarters of recovery, real GNP was 7.5 percent above its rate at the cyclical peak. In contrast, output was only 2.4 percent higher than the prior cyclical peak after six quarters of the most recent recovery. The difference of about five percent in this pattern since the recession trough ( $I / 1975)$ is called the "persisting output gap" by the CBO.

Chart IV shows the corresponding developments for civilian employment. The employment pattern in the recent recovery is not different from that of prior recoveries. The shortfall of output is not associated with a shortfall of employment. Recent unemployment experience is not explained by unusual employment developments but rather is apparently due to unusual labor force behavior. Thus, it appears that the "output gap" might better be termed a "productivity gap." The decline in labor productivity of about five percent would be expected due to the impact on actual and potential output of the higher relative price of energy.

A more conservative estimate of the loss in potential output may be found using the earlier evidence on the loss of economic capacity in manufacturing. About 20 percent of real GNP is comprised of compensation of government employees, output originating in the rest of the world, and output produced by the residential housing stock. There is little reason to expect that these components of output are as severely limited by the change in the energy price as the output of the rest of the economy. Assuming the manufacturing result is representative for the remainder of the private economy, a conservative estimate of the loss in potential output is four percent.

The theory above indicates that the rise in the relative price of energy would cause a percentage rise in the minimum price level associated with potential

\footnotetext{
27U.S. Congress, Congressional Budget Office, The Disappointing Recovery, January 11, 1977, pp. 1-3.

28 Ibid., p. 3.
}

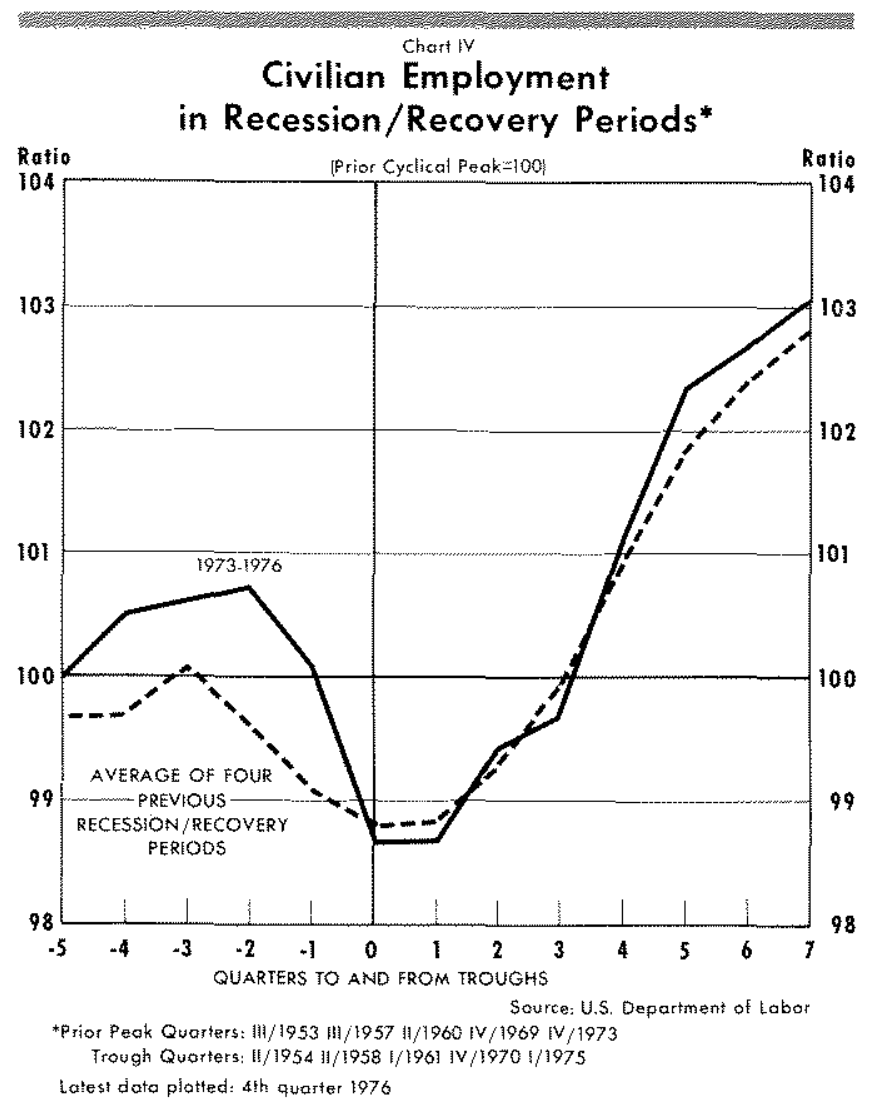

output, equal in size to the percentage loss in potential output. Thus, a minimum four percent and perhaps a five percent rise in the price level over 1974 would be expected based upon supply considerations alone. The actual rate of price increase, as measured by the GNP deflator, was 11.5 percent. If roughly four percentage points of this increase is accounted for by the one-time price level effect of the increase in the relative price of energy, the remainder, 7.5 percent, must be accounted for by other factors, such as growth in aggregate demand.

The impact of a four percent reduction in potential GNP may be seen in Chart $V$, which measures actual real GNP relative to potential output with and without the four percent reduction. The Chart indicates that in the fourth quarter of last year the economy was producing 92.6 percent of the CEA's measure of potential output. To account for the effect of the energy price change, the CEA estimate of potential output is lowered after the fourth quarter of 1973 so that, by the fourth quarter of 1974 , potential output is four percent lower. The CEA estimate of the growth rate of potential output ( 3.5 percent) is maintained in the adjusted curve after the fourth quarter of 1974. As the Chart indicates, by the end of 1976 the economy 


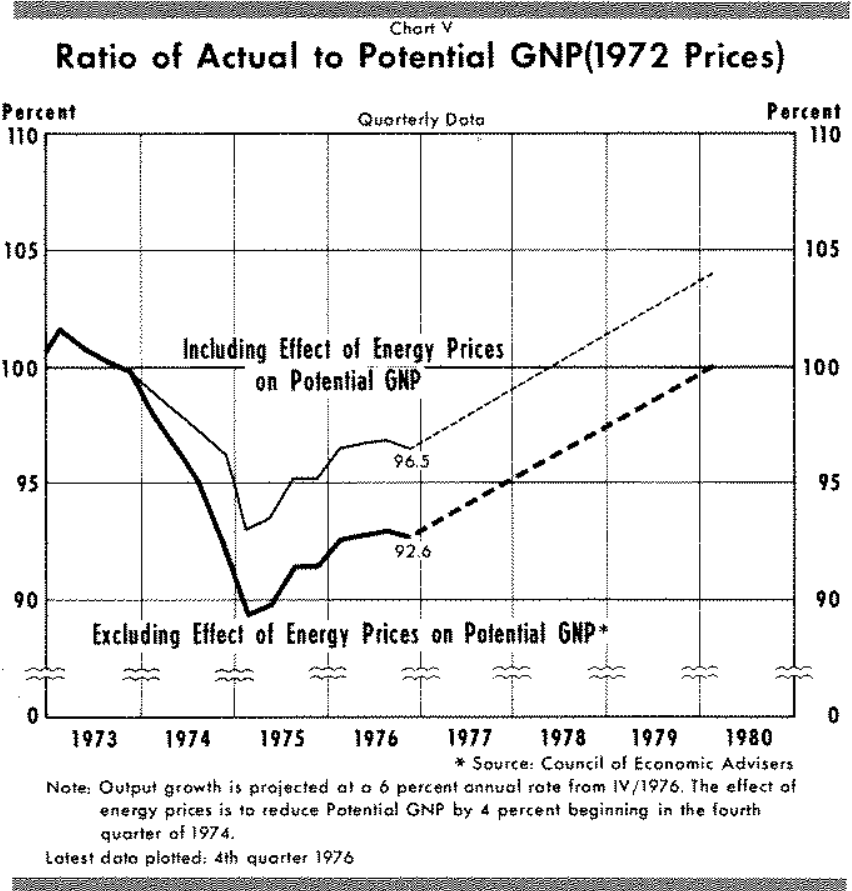

was producing 96.5 percent of potential output or the gap is less than half as large as the official measures indicate.

Recent policy discussions seem to assume that demand management policies can close the official gap. Obviously, policy measures which are sufficient for this size task would be far too great for the resources at hand. The biggest output gain achievable through stabilization policy is about $\$ 46$ billion in the fourth quarter of 1976. Attempts to close the official gap of over $\$ 100$ billion reflect a failure to recognize that the implied production rate is unattainable and that such efforts will add to the rate of price increase.

More importantly, Chart $\mathrm{V}$ illustrates the importance of accounting for the loss in potential output in assessing both the prospects for closing the gap, and the desirability of policy stimulus. How quickly the gap closes depends upon the rate of growth of actual output. In Chart $V$ each measure of potential output grows at 3.5 percent and actual real GNP is allowed to grow at a six percent annual rate, a growth goal which has been the subject of considerable recent discussion. When account is taken of the effect of the energy price increase on potential output, the Chart indicates that six percent growth closes the gap early next year. Of course, beyond that point real output growth would be limited to the 3.5 percent growth in potential output. If the official estimates of potential output are correct, achieving the growth goal would not close the gap until 1980. Thus, much of the current debate over the need for fiscal stimulus rests upon an awareness of the permanent loss in potential output since $1973 .^{29}$

"Even if real outpat grows at about a five percent annual rate, less than the average annual rate of growth of real output achieved during the recovery (1/1975 to IV/1976), the gap would be eliminated by the end of next year, rather than in 1982 , as the official gap would indicate. 